\title{
PENURUNAN COD AIR LIMBAH INDUSTRI PENYAMAKAN KULIT MENGGUNAKAN REAGEN FENTON
}

\section{REDUCTION OF COD IN TANNERY WASTEWATER USING FENTON'S REAGENT}

\author{
Muhammad Sholeh, Supraptiningsih, Wahyu Pradana A. \\ Balai Besar Kulit, Karet dan Plastik, Yogyakarta \\ Email: sholeh_tahunan@yahoo.com \\ Diterima: 10 Februari 2013 Direvisi: 16 April 2013 Disetujui: 15 Mei 2013
}

\begin{abstract}
The aim of the experiment was to obtain optimum condition for COD reduction in tannery wastewater using fenton's reagent. The effects of different reaction parameters included ferrous concentration, hydrogen peroxide concentration, and the $\mathrm{pH}$ walue of solution were investigated. The optimum values were achieved at 0.2\%, $120 \mathrm{ppm}$, and 4 for $\mathrm{FeSO}_{4}, \mathrm{H}_{2} \mathrm{O}_{2}$, and $\mathrm{pH}$, respectively. The optimum condition still unable to fulfill the quality standard for COD of wastewater.
\end{abstract}

Keywords: tannery, wastewater, fenton's reagent, chemical oxygen demand

\begin{abstract}
ABSTRAK
Penelitian ini bertujuan untuk memperoleh kondisi operasi yang optimum pengolahan air limbah industri penyamakan kulit menggunakan reagen fenton. Variasi parameter reaksi yang diteliti yaitu konsentrasi fero sulfat, konsentrasi hidrogen peroksida, dan $\mathrm{pH}$ larutan. Kondisi operasi optimum yang diperoleh yaitu pada konsentrasi $\mathrm{FeSO}_{4}=0,2 \%$, konsentrasi $\mathrm{H}_{2} \mathrm{O}_{2}=120$ $\mathrm{ppm}$, dan $\mathrm{pH}=4$. Kondisi operasi optimum yang diperoleh belum mampu untuk menurunkan kadar COD sampai dibawah baku mutu.
\end{abstract}

Kata kunci: industri penyamakan kulit, air limbah, reagen fenton, chemical oxygen demand

\section{PENDAHULUAN}

Industri penyamakan kulit menghasilkan limbah cair dengan volume cukup besar yang mengandung beban polutan organik dan anorganik yang tinggi. Selain itu intensitas warna limbah ini juga tinggi karena mengandung sisa warna, bahan kimia, dan bahan penyamak (Srinivasan et al., 2011). Toksisitas limbah cair industri penyamakan kulit lebih tinggi dibandingkan dengan limbah cair industri tekstil dan kertas (Verma, 2011). Baku mutu COD maksimum yang diperbolehkan dalam buangan air limbah industri penyamakan kulit untuk proses penyamakan kulit menggunakan krom dari kulit mentah garaman yaitu $100 \mathrm{mg} / \mathrm{L}$
(Gubernur DIY, 1998). Pengolahan tersier perlu dilakukan untuk menjamin buangan air limbah dapat memenuhi baku mutu di atas karena polutan berupa pewarna pada umumnya cukup stabil terhadap cahaya, panas, oksidator dan sulit didegradasi secara biologis.

Penggunaan teknologi alternatif yang bertujuan untuk mengubah molekul refraktori menjadi senyawa lain yang bisa lebih jauh biodegradabel, menjadi perhatian banyak peneliti. Proses oksidasi lanjut (advanced oxidation processes) telah digunakan untuk pengolahan air limbah yang mengandung senyawa organik berbahaya seperti pestisida, surfaktan, dan pewarna. Advanced oxidation 
processes (AOPS) telah berhasil digunakan sebagai metode pretreatment untuk mengurangi konsentrasi senyawa organik beracun yang menghambat pengolahan air limbah proses biologis (Stasinakis, 2008).

Mekanisme utama dari fungsi AOPs adalah generasi radikal bebas yang sangat reaktif. Radikal hidroksil (HO) yang efektif dalam menghancurkan kimia organik karena bereaksi dengan cepat dan non selektif dengan hampir semua senyawa organik yang kaya elektron. Radikal ini mampu memineralisasi sebagian substrat, yaitu mereduksinya menjadi $\mathrm{CO}_{2}$ dan $\mathrm{H}_{2} \mathrm{O}$ (Hernandez et al., 2009). Teknik ini dipakai banyak peneliti untuk mendegradasi polutan dalam air limbah, diantaranya pewarna sintetis (Vatanpour et al., 2009; Ozcan et al., 2009; Hernandez et al., 2009), dan landfill leachate (Atmaca, 2009).

AOPs yang paling penting yaitu sistem Fenton, yang terdiri dari reaksi $\mathrm{H}_{2} \mathrm{O}_{2}$ dengan $\mathrm{Fe}^{2+}$ membentuk ${ }^{\bullet} \mathrm{OH}$. Hidrogen peroksida merupakan senyawa yang ramah lingkungan karena meninggalkan $\mathrm{O}_{2}$ dan air sebagai produk samping. Senyawa ini digunakan sebagai desinfektan di dunia medis dan industri serta sebagai oksidan dalam sintesis produk dan pengolahan air limbah. Penggunaan langsung hidrogen peroksida untuk pengolahan air limbah terbatas karena kemampuan oksidasinya yang rendah (Hernandez et al., 2009)

Reaksi fenton melibatkan beberapa tahapan dimana radikal bebas hidroksil $\left({ }^{\circ} \mathrm{OH}\right)$ dan hidroksiperoksil $\left(\mathrm{HO}_{2}{ }^{\circ}\right)$ merupakan hasil antara yang menjadi kunci. Mekanisme pembentukan readikal bebas yaitu sebagai berikut (Vatanpour et al., 2009):

$$
\begin{aligned}
& \mathrm{Fe}^{2+}+\mathrm{H}_{2} \mathrm{O}_{2} \rightarrow \mathrm{Fe}^{3+}+{ }^{\bullet} \mathrm{OH}+\mathrm{OH}^{-} \\
& { }^{\circ} \mathrm{OH}+\mathrm{H}_{2} \mathrm{O}_{2} \rightarrow \mathrm{H}_{2} \mathrm{O}+\mathrm{HO}_{2} \\
& \mathrm{Fe}^{3+}+\mathrm{HO}_{2}{ }^{-} \rightarrow \mathrm{Fe}^{2+}+\mathrm{H}^{+}+\mathrm{O}_{2} \\
& \mathrm{Fe}^{2+}+\mathrm{HO}_{2} \rightarrow \mathrm{Fe}^{3+}+\mathrm{HO}_{2}^{-} \\
& \mathrm{Fe}^{2+}+{ }^{\circ} \mathrm{OH} \rightarrow \mathrm{Fe}^{3+}+\mathrm{OH}^{-}
\end{aligned}
$$

Penelitian ini bertujuan untuk memperoleh kondisi operasi yang optimum pengolahan air limbah industri penyamakan kulit menggunakan reagen fenton.

\section{BAHAN DAN METODE}

\section{Bahan Penelitian}

Air limbah industri penyamakan kulit, diperoleh dari Laboratorium Penyamakan Kulit Sitimulyo, Balai Besar Kulit, Karet, dan Plastik, Yogyakarta. Air limbah diambil dari outlet pengolahan sekunder. Hidrogen Peroksida $30 \%$, Fero Sulfat, Sodium hidroksida, dan Asam Sulfat, semuanya analytical grade (Merck).

\section{Alat}

Pengaduk magnetis dan $\mathrm{pH}$ meter.

\section{Metode}

Air limbah $500 \mathrm{~mL}$ dimasukkan ke dalam gelas beker. Limbah diaduk dengan magnetic stirrer pada kecepatan $300 \mathrm{rpm}$. Selanjutnya dimasukkan reagen fenton yang berupa fero sulfat dan hidrogen peroksida. Konsentrasi fero sulfat divariasikan $0 \%$, $0,04 \%, 0,08 \%, 0,12 \%, 0,16 \%$, dan $0,20 \%$. Konsentrasi hidrogen peroksida divariasikan 0, 30 ppm, 60 ppm, 120 ppm, 180 ppm, 240 ppm, dan 300 ppm. pH divariasikan 3, 4, 5, 6, dan 7. Pengadukan dijalankan selama 15 menit, selanjutnya flok terbentuk dibiarkan mengendap sampai sempurna. Beningan diambil untuk diuji kadar polutannya.

\section{HASIL DAN PEMBAHASAN}

\section{Pengaruh konsentrasi hidrogen peroksida}

Hidrogen peroksida memiliki peran penting sebagai sumber $\mathrm{OH}$ pada reaksi fenton. Dari hasil percobaan, apabila hanya $\mathrm{FeSO}_{4}$ yang ditambahkan ke dalam limbah, nilai COD yang diperoleh justru lebih tinggi daripada COD tanpa perlakuan dengan reagen fenton. Terlihat dalam Gambar 1, COD limbah sebelum perlakuan dengan reagen fenton sebesar $250,9 \mathrm{mg} / \mathrm{L}$ dan setelah perlakuan dengan reagen fenton menjadi $322,1 \mathrm{mg} / \mathrm{L}$. Terjadi kenaikan nilai COD sebanyak 28,4 \%. Hal ini disebabkan selama perlakuan, $\mathrm{Fe}^{2+}$ tidak teroksidasi menjadi $\mathrm{Fe}^{3+}$. Akibatnya tidak terbentuk flok dan ion $\mathrm{Fe}^{2+}$ banyak yang terlarut dalam limbah. Saat diuji COD terhadap limbah ini, terjadi reaksi oksidasi $\mathrm{Fe}^{2+}$ oleh $\mathrm{Cr}_{2} \mathrm{O}_{7}^{2-}$ dengan reaksi sebagai berikut: 
$6 \mathrm{Fe}^{2+}+\mathrm{Cr}_{2} \mathrm{O}_{7}^{2-}+14 \mathrm{H}^{+} \rightarrow 6 \mathrm{Fe}^{3+}+2 \mathrm{Cr}^{3+}+7 \mathrm{H}_{2} \mathrm{O}$

Karena $\mathrm{Cr}_{2} \mathrm{O}_{7}{ }^{2-}$ tidak hanya mengoksidasi limbah namun juga $\mathrm{Fe}^{2+}$, maka COD yang diperoleh nilainya lebih tinggi.

Penambahan dosis $\mathrm{H}_{2} \mathrm{O}_{2}$ yang semakin besar dari 30 ppm sampai dengan 120 ppm menyebabkan pengurangan COD semakin besar dari $22,7 \%$ sampai dengan $30,7 \%$. Hal ini sebagai efek bertambahnya radikal ${ }^{\circ} \mathrm{OH}$ yang terbentuk. Namun dosis hidrogen peroksida di atas 120 ppm justru menghasilkan pengurangan COD yang semakin kecil. Hal ini kemungkinan disebabkan terbentuknya radikal hidroperoksil ${ }^{\circ} \mathrm{OOH}$ pada konsentrasi $\mathrm{H}_{2} \mathrm{O}_{2}$ yang semakin besar. Radikal ${ }^{\bullet} \mathrm{OOH}$ mempunyai potensial oksidasi yang jauh lebih kecil dibandingkan dengan ${ }^{\circ} \mathrm{OH}$ (Chen and Wu, 2009; Hassan and Hameed, 2011; Bouasla et al., 2012).

\section{Pengaruh konsentrasi fero sulfat}

Pengaruh konsentrasi fero sulfat pada pengurangan COD terlihat pada Gambar 2 . Konsentrasi $\mathrm{H}_{2} \mathrm{O}_{2}$ diambil yang memberikan nilai penurunan COD terbesar pada percobaan point a yaitu sebesar $120 \mathrm{ppm}$. Penambahan hidrogen peroksida tanpa disertai fero sulfat hanya mampu mengurangi COD sebesar $11,8 \%$. Semakin besar konsentrasi fero sulfat, semakin meningkat pula oksidasi terhadap polutan yang ditunjukkan dengan semakin besarnya

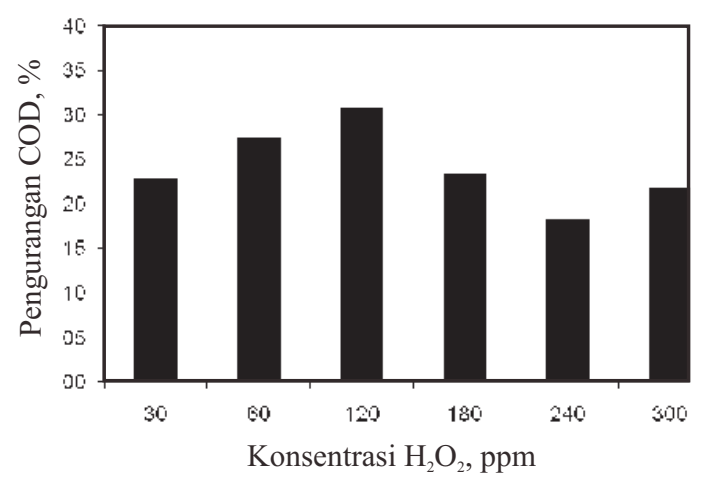

Gambar 1. Pengaruh konsentrasi hidrogen peroksida terhadap pengurangan nilai COD. Kondisi percobaan: Konsentrasi $\mathrm{FeSO}_{4}=0,12$ $\%$; $\mathrm{pH}$ awal $=8,3$; COD limbah tanpa proses fenton $($ kontrol $)=250,9 \mathrm{mg} / \mathrm{L}$. pengurangan COD dalam limbah. Hal ini disebabkan semakin banyaknya radikal hidroksil yang terbentuk (Achille and Yilian, 2010). Hasil senada juga ditemukan oleh Mousavi et al. (2011), Masomboon et al. (2011) dan Hashemian et al. (2013). Pengurangan COD terbesar yaitu 35,2\% diperoleh pada konsentrasi $\mathrm{FeSO}_{4} 0,2 \%$.

\section{Pengaruh pH}

Terlihat dari Gambar 3 bahwa $\mathrm{pH}$ netral menghasilkan penurunan COD yang rendah. Hal ini disebabkan pembentukan ferric hydroxo-complexes $\left[\mathrm{Fe}_{2}(\mathrm{OH})_{3}\right]_{3+}$ yang menghalangi reaksi antara $\mathrm{Fe}^{3+}$ dengan hidrogen peroksida serta regenerasi $\mathrm{Fe}^{2+} . \mathrm{Fe}^{3+}$ terendapkan sebagai $\mathrm{Fe}(\mathrm{OH})_{3}$ dimana senyawa ini mengkatalisis dekomposisi $\mathrm{H}_{2} \mathrm{O}_{2}$ menjadi oksigen dan air. Akibatnya kemampuan oksidasi hidrogen peroksida menjadi berkurang (Achille and Yilian, 2010; Mahmood et al., 2011). Diperoleh penurunan COD optimum sebesar 33,3\% pada $\mathrm{pH}=4$.

Dari tiga variasi parameter yang dilakukan, diperoleh kondisi optimum pada konsentrasi $\mathrm{FeSO}_{4}=0,2 \%$, konsentrasi $\mathrm{H}_{2} \mathrm{O}_{2}=$ $120 \mathrm{ppm}$, dan $\mathrm{pH}=4$. Proses fenton di sini diaplikasikan sebagai pengolahan tersier, dimana $\mathrm{pH}$ optimum sebesar 4 tidak praktis bila digunakan. Variasi $\mathrm{pH}$ dilakukan untuk mengetahui sejauh mana inefisiensi proses fenton bila dilakukan tanpa penyesuaian $\mathrm{pH}$ limbah terlebih dahulu dibandingkan dengan pada $\mathrm{pH}$ optimum. Penurunan COD pada $\mathrm{pH} 7$ dibandingkan dengan pada $\mathrm{pH} 4$ diperoleh sebesar $68,0 \%$.

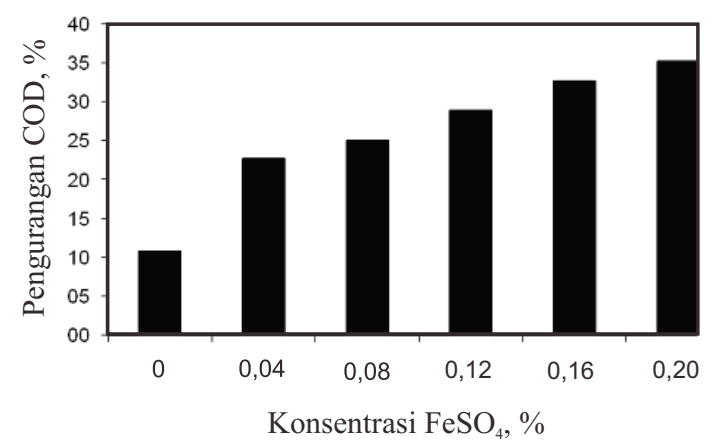

Gambar 2. Pengaruh konsentrasi fero sulfat terhadap pengurangan nilai COD. Kondisi percobaan: Konsentrasi $\mathrm{H}_{2} \mathrm{O}_{2}=120$ ppm; $\mathrm{pH}$ awal $=8,3$; COD limbah tanpa proses fenton (kontrol) $=250,9 \mathrm{mg} / \mathrm{L}$. 


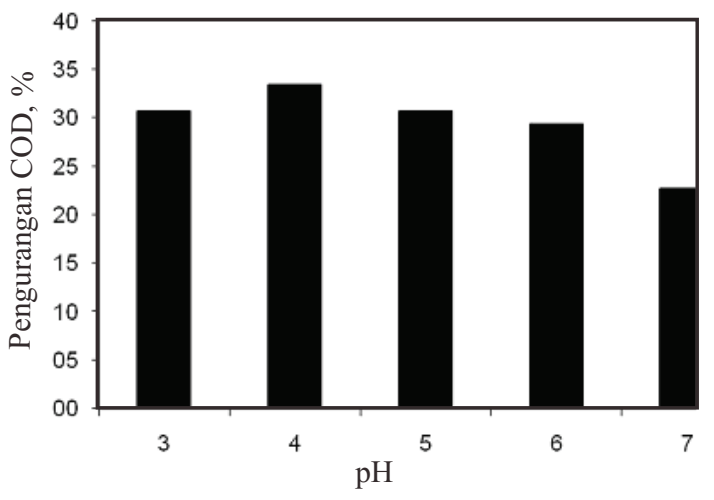

Gambar 3. Pengaruh $\mathrm{pH}$ terhadap pengurangan nilai COD. Kondisi percobaan: Konsentrasi $\mathrm{FeSO}_{4}=0,2 \%$; konsentrasi $\mathrm{H}_{2} \mathrm{O}_{2}$ $=120$ ppm; COD limbah tanpa proses fenton (kontrol) $=250,9 \mathrm{mg} / \mathrm{L}$.

Baku mutu COD maksimum yang diperbolehkan dalam buangan air limbah industri penyamakan kulit untuk proses penyamakan kulit menggunakan krom dari kulit mentah garaman yaitu $100 \mathrm{mg} / \mathrm{L}$ (Gubernur DIY, 1998). Setelah perlakuan dengan fenton, belum diperoleh kadar COD limbah yang memenuhi baku mutu.

\section{KESIMPULAN DAN SARAN}

\section{Kesimpulan}

Konsentrasi regen fenton $\left(\mathrm{FeSO}_{4}\right.$ dan $\mathrm{H}_{2} \mathrm{O}_{2}$ ) dan $\mathrm{pH}$ berpengaruh terhadap penurunan COD air limbah industri penyamakan kulit. Kondisi operasi optimum yang diperoleh yaitu pada konsentrasi $\mathrm{FeSO}_{4}=$ $0,2 \%$, konsentrasi $\mathrm{H}_{2} \mathrm{O}_{2}=120 \mathrm{ppm}$, dan $\mathrm{pH}=$ 4. Kondisi operasi optimum yang diperoleh belum mampu untuk menurunkan kadar COD sampai dibawah baku mutu.

\section{Saran}

Melihat kondisi optimum penurunan COD diperoleh pada $\mathrm{pH}=4$, maka perlu dicoba pemanfaatan reagen fenton untuk mengurangi COD air limbah proses pengecatan.

\section{UCAPAN TERIMA KASIH}

Penulis mengucapkan terima kasih kepada Balai Besar Kulit, Karet, dan Plastik yang telah membiayai penelitian ini melalui dana DIPA.

\section{DAFTAR PUSTAKA}

Achille, G. N. and Yilian, L., 2010. Mineralization of organic compounds in wastewater contaminated with petroleum hydrocarbon using Fenton's reagent: a kinetic study, Journal of American Science, 6(4): 58-66.

Atmaca, E., 2009. Treatment of landfill leachate by using electro-Fenton method, Journal of Hazardous Materials, 163: 109114.

Bouasla, C., Ismail, F. and Samar, M. E., 2012. Effect of operator parameters, anions and cations on the degradation of AY99 in an aqueous solution using Fenton's reagent. Optimization and kinetics study, International Journal of Industrial Chemistry, 3 (15): 1-11.

Chen, C. C. and Wu, R. J., 2009. Chemical oxidative degradation of acridine orange dye in aqueous solution by Fenton's reagent, Journal of the Chinese Chemical Society, 56: 1147-1155.

Gubernur DIY, 1998. Keputusan Gubernur Kepala Daerah Istimewa Yogyakarta nomor 281/KPTS/1998 tentang Baku Mutu Limbah Cair Bagi Kegiatan Industri di Propinsi Daerah Istimewa Yogyakarta.

Hashemian, S., Tabatabaee, M. and Gafari, M., 2013. Fenton oxidation of methyl violet in aqueous solution, Journal of Chemistry, doi:10.1155/2013/509097.

Hassan, H. and Hameed, B. H., 2011, Fentonlike oxidation of red 1 solutions using heterogeneous catalyst based on ball clay, International Journal of Environmental Science and Development, 2(3): 218-222.

Hernández, J. M. P., Huitle, C. A. M., Mar, J. L. G. and Ramírez, A. H., 2009. Recent advances in the application of electrofenton and photoelectro-fenton process for removal of synthetic dyes in wastewater treatment, Journal of Environmental Engineering Management, 19(5): 257-265.

Mahmood, A., Ali, S., Saleem, H. and Hussain, T., 2011. Optimization for degradation of commercial reactive yellow dye 145 through Fenton's reagent, Asian Journal of Chemistry, 23(9): 3875-3878. 
Masomboon, N, Ratanatamskul, C. and MingChun, L., 2011. Kinetics of 2,6dimethylaniline oxidation by various Fenton processes, Journal of Hazardous Materials, 192: 347-353.

Mousavi, S. A. R., Mahvi, A. H., Nasseri, S. and Ghafari, S., 2011. Effect of Fenton process $\left(\mathrm{H}_{2} \mathrm{O}_{2} / \mathrm{Fe} 2+\right)$ on removal of linear alkylbenzene sulfonate using central composite, Iranian Journal Environmental Health Science and Engineering, 8(2): 129-138.

Özcan, A. Şahin, Y., Koparal, A. S. and Oturan, M. A., 2009. Electro-fenton removal of the cationic dye basic blue 3 by using carbon felt cathode, Journal of Environmental Engineering Management, 19(5):267-275.

Srinivasan, S. V., Mary, G. P. S., Kalyanaraman, C., Sureshkumar, S.,Balakameswari, K. S. and
Suthanthararajan, R., 2010. Combined advanced oxidation and biological treatment of tannery effluent, Clean Technologies and Environmental Policy, doi:10.1007/s10098-011-0393$\mathrm{x}$.

Stasinakis, A.S., 2008. Use of selected advanced oxidation processes (AOPs) for wastewater treatment a mini review, Global NEST Journal, 10(3): 376-385.

Vatanpour, V., Daneshvar, N. and Rasoulifard, H., 2009. Electro-fenton degradation of synthetic dye mixture: influence of intermediate, Journal of Environmental Engineering Management,19(5): 277282.

Verma, Y., 2011, Toxicity assessment of dye containing industrial effluents by acute toxicity test using daphnia magna, Toxicology and Industrial Health, 27(1): 41-9. 
